AEA, LXXV, 2002, 298, pp. 191 a 216. ISSN: 0004-0428

\title{
VARIA
}

\section{SOBRE EL SAN JUAN EN PATMOS DE EL MUDO}

Entre los navarretes escurialenses de primera hora, no todos expresamente citados en las cuentas del monasterio, están las ocho pinturas que adornaron durante años el claustro alto, realizadas por el Mudo entre su incorporación plena en 1569 a la nómina de los artistas de Felipe II y 1575 , después de haber dejado patente su capacidad como copista. En primer lugar hubo de hacer el riojano los cuatro lienzos destinados a los retablos de la llamada sacristía de prestado, ubicada junto a la escalera del claustro principal, y a continuación pintó los cuatro que ocuparían los altares de la sacristía del colegio situada al otro lado de aquélla, según refiere fray José de Sigüenza ', quien llegó a El Escorial cuando ya Navarrete había desaparecido. Los cuatro primeros fueron, así, el San Jerónimo penitente, firmado ya en 1569, la Asunción de la Virgen, el Martirio de Santiago y el Martirio de San Felipe Apóstol ${ }^{2}$, todos ellos creados en Logroño, donde el pintor se había trasladado, con autorización expresa del monarca, debido a su delicado estado de salud, y su entrega al monasterio se efectuó en la primavera de $1571^{3}$. Por otoño de este año hubo de recibir el encargo de la segunda serie, compuesta por la Sagrada Familia con San Joaquín y Santa Ana, la Flagelación, la Adoración de los Pastores y San Juan en Patmos. Obtuvo entonces permiso para residir en Madrid ${ }^{4}$, siempre en atención a su quebrantada salud, verdadera causa de la tardanza de casi cuatro años en ultimar su labor. Las cuatro nuevas pinturas serían pagadas en 3 de enero de 1576, de conformidad con lo establecido por cédula real de 19 de noviembre de $1575^{5}$, apenas un año antes de que, calibrando mal sus mermadas fuerzas, se le encomendaran los altares de la basílica. Los ocho lienzos fueron vistos ya por Fr. José de Sigüenza en el claustro alto, y hubo de ser precisamente a raíz de su traslado al nuevo emplazamiento cuando se encargó su limpieza a Miguel Barroso, a quien en 1590 se abonaba cierta suma por «lavar» ocho cuadros de El Mudo que allí estaban ${ }^{6}$.

' Fr. José de Sigüenza, Fundación del Monasterio de El Escorial, ed. de Madrid, Aguilar, 1963, parte II, discurso V, p. 241

${ }^{2}$ Ibid. p., 242

${ }^{3}$ El dato está en A. Ceán Bermúdez, Diccionario histórico de los más ilutre profesores de las Bellas Arte en España, Madrid, 1800, vol. II, p. 95; recogido por C. García Frías en Navarrete «el Mudo», pintor de Felipe II (seguidores y copias), Catálogo de la Exposición, Logroño-El Escorial, 1995, p. 268.

${ }_{4}^{4}$ Julián Zarco Cuevas, Pintores españoles en San Lorenzo el Real de El Escorial (1566-1613) Madrid, 1931, p. 33. En realidad no existe documento en el que se hable de estas cuatros pinturas hasta su entrega en 1575 . R. Mulcahy (Catálogo de la exposición de 1995, p. 157) da por cierto que el encargo se hizo en este momento.

${ }^{5}$ Zarco Cuevas, op. cit., p. 35-36. Estas cuatro pinturas se valoraron conjuntamente en 800 ducados.

${ }^{6} \mathrm{G}$. de Andrés, «Inventario de documentos sobre la construcción y ornato del monasterio del Escorial existentes en el Archivo de su Real Biblioteca», anejo de A.,E.A, 1972, p. 188. De la tasación, que incluye también la de algunas pinturas originales de Barroso, se encargó Pellegrino Tibaldi. 
Como es sabido, se conservan sólo cinco de las ocho pinturas: el San Jerónimo penitente, el Martirio de Santiago, la Sagrada Familia con San Joaquín y Santa Ana, la Flagelación y la Adoración de los Pastores; todas en el monasterio. La suerte de las tres restantes parece ligada al incendio de 1671. Pero no hay unanimidad de testimonios sobre las verdaderas consecuencias de este suceso ni aun sobre el tema iconográfico específico de la referida a San Felipe; y la Asunción de la Virgen es mencionada en ocasiones como una simple Madonna. De la de San Juan en Patmos - las cuentas hablan no obstante de San Juan Bautista ${ }^{7}$ - tenemos por el contrario una descripción bastante precisa debida a fray José de Sigüenza, quien al considerar las pinturas de El Mudo localizadas en el claustro alto principal, y siguiendo una exposición ajustada a lo cronológico e interesada en dejar patente las diferencias estilísticas habidas, por «tanta mundanza (que) hizo de los unos a los otros en la manera de pintar», presta desigual atención a unas y otras, y tras referirse a las cuatro primeras, a la Natividad y a la Sagrada Familia, y sólo antes de ocuparse de la Flagelación de Cristo, indica: «El otro cuadro es de San Juan Evangelista escribiendo el Apocalipsis en la isla de Patmos. Una figura valiente, como ellos dicen, galanamente plantada, de singular meneo, elevado el rostro, con un escorzo acertadísimo, porque tenía gracia en esto, el colorido de hombre varonil, extremado, vestido y ropas con mucho adorno, grave y hermoso; la campaña y los lejos llenos de arboleda y frescura, con algunas visiones sagradas muy remontadas y casi imperceptibles, como lo que de ellas escribió lo es para los ojos de los hombres. Un águila, que desalada se abatió sobre una presa en una rana, que se descubre un poco en una fuente, que así lo hizo el Verbo Eterno para sacarnos del lodo de nuestra miseria, incorporándonos en sí» ${ }^{8}$. Esta es la pintura objeto de nuestro interés.

La descripción se ajusta a lo anotado en la Segunda Entrega de los objetos de valor cedidos por Felipe II a El Escorial: «otro lienço de pintura de la figura de Sant Juan Evangelista escriuiendo en un libro con un águila a los pies, vestido con una ropa colorada, con paysages de la misma mano, puesto sobre tabla, del tamaño y guarnición que el de la partida antes désta» ${ }^{9}$. Los últimos datos se refieren a la bien conocida pintura de Cristo a la columna (3.50 $\times 2.10 \mathrm{~m}$.). Interesa también la información sobre las ropas del apóstol y sobre la particularidad del soporte, lienzo sobre tabla.

Testimonio parecido al de Sigüenza es el facilitado en 1657 por el padre Francisco de los Santos, quien se refiere a la obra como un cuadro de «San Juan excriuiendo el Apocalypsi en la Isla de Padmos, eleuado el rostro a las visiones sagradas, que se descubren, remontadas en muy altos términos; las distancias de la campaña con muchos Arboles, y frescura, y un Aguila junto a él, significando la altura de sus escritos; famoso cuadro, casi se inclina la sensura a darle ventaja entre todos» ${ }^{10}$.

En la descripción facilitada en 1626 por el erudito, mecenas y coleccionista Cassiano del Pozzo, integrante de la misión diplomática papal encabezada por cardenal Francesco Barberini, se mencionan varias pinturas el claustro alto, siempre en términos ponderativos, como era de esperar en un hombre de su sensibilidad ante las creaciones de El Mudo. Cita así el Cristo

\footnotetext{
${ }^{7}$ Zarco Cuevas, op. cit. . pp. 35-36. Así también en G. de Andrés, art. cit. , anejo de A.,E.A, 1972, p. 44 . La Sagrada Familia aparece como «Nuestra Señora con el Niño Jesús en los braços y otras figuras».

${ }^{8}$ J. de Sigüenza, op. cit. , parte II, discurso V, p. 244. En realidad Sigüenza describe también a Asunción de la Virgen en términos bastante inequívocos.

9 2. ${ }^{\circ}$ E., 98-99, citado por Zarco Cuevas («Inventario de alhajas, relicarios, estatuas, pinturas, tapices y otros objetos de valor y curiosidad donados por el rey Felipe II al monasterio de El Escorial, Año 1571-1598», en Boletín de la Real Academia de la Historia, núm. 96; 1930, n. 897, p. 666). El autor señala que se destruyó en el incendio de 1671. El número 896 corresponde al Cristo a la columna.

${ }^{10}$ Francisco de los Santos, Descripción breve del monasterio de San Lorenzo el Real del Escorial única maravilla del mundo. Madrid, 1657, fol. $62 \mathrm{v}$.
}

AEA, LXXV, 2002, 298, pp. 191 a 216 
a la columna y los otros lienzos del riojano, terminando su enumeración con una referencia a «un S. Giovanni con un bellisimo paese e alberami, che mostra, he scriuese Apocalisse» ${ }^{11}$. Enriqueta Harris y Gregorio de Andrés subrayan que los cuadros a que se refiere el ilustre visitante eran los que estaban en los ángulos del claustro principal. Es de notar, sin embargo, que en su relación se habla de una Madonna y de una Asunción de la Virgen, como dos creaciones distintas, y que la pintura del Martirio de San Felipe es mencionada como de la Predicación del santo, lo que si bien contradice a Sigüenza y al P. de los Santos parece confirmar la descripción facilitada ya en 1594 del Doctor Almela, sin que sepamos con plena certeza de qué lado está la verdad ${ }^{12}$. El anónimo testimonio de un erudito pintor sevillano que visitó el Escorial a fines del s. xvil, acaso por 1698 — después, en suma, del incendio de 1671—, nada detalla de las pinturas que había en el claustro, limitándose a indicar con carácter general que «de españoles hay mil tesoros; de Becerra, del Mudo... llamado el Tiziano español, de Alonso Sanches Coello...», para terminar recalcando — sevillanía obliga- que en tan espléndido conjunto sólo se echaban en falta creaciones del mismísimo Murillo ${ }^{13}$. Y no es mayor lo que sobre el particular aporta la descripción del P. Andrés Ximénez, ya de 1764.

Un inventario anónimo de las pinturas escurialenses realizado en 1776, publicado con notas de Ángel Custodio de la Vega ${ }^{14}$, menciona en el claustro principal alto un Martirio de Santiago y un Nacimiento de El Mudo, un Cristo a la columna y una Sagrada Familia, sin indicación de autor, y una pintura de Cristo apareciéndose a su madre ${ }^{15}$ y un San Jerónimo penitente, también de El Mudo, pero nada se dice ya del Martirio de San Felipe, de la Asunción, o del San Juan en Patmos ${ }^{16}$, que difícilmente ha de ser el Apóstol que, sin mayores precisiones, se cita como de autor desconocido. Vicente Poleró ${ }^{17}$ afirma, al tratar de estas pinturas del claustro, que la Asunción de la Virgen, el San Juan Evangelista en la isla de Patmos y el San Felipe —nada precisa del pasaje representado-, perecieron en un incendio ${ }^{18}$. También Ceán Bermúdez da por cierto que el lienzo de San Juan se destruyó en $1671{ }^{19}$, opinión compartida en general por los autores modernos, desde Zarco Cuevas a Rosemary Mulcahy ${ }^{20}$. Gregorio de Andrés y Enriqueta Harris indican no obstante que en el incendio de 1671 sufrieron serios desperfectos las pinturas de la Madonna y de San Felipe, que fueron

"Enriqueta Harris y Gregorio de Andrés, «Descripción de El Escorial por Cassiano del Pozzo (1626)», anejo a A.E.A. núm. 179, XLV, 1972, p. 18.

${ }^{12}$ Se dice que era de San Felipe cuando echó del ídolo al demonio en forma de dragón, «Descripción de la Octava Maravilla del Mundo por el Doctor Almela en el año 1594» publicada por Gregorio de Andrés, t. VI. de los Documentos para la historia del monasterio de San Lorenzo el Real de El Escorial..., Madrid, 1962, p. 52 Así en en la Primera entrega, núm. 196; ver núm. 892 de J. Zarco Cueva «Inventario de las alhajas...».

${ }_{13}$ G. de Andrés, «Relación anónima del s. XVIl sobre los cuadros de El Escorial», XLIV, n. 173, 1972, pp. $49-64$.

14 «Verdadero orden de las pinturas del Escorial en los sitios que están colocadas con los nombres de sus autores, año 1776...», en Documentos para la Historia del Monasterio de El Escorial», V. 1962, pp.226 y ss. La edición definitiva del Viage de España de Ponz es ya de 1778.

${ }^{15}$ Es obra que Sigüenza vió en el Capítulo, (op. cit., p. 385), ajena desde luego a las series de las sacristías provisioneles y de otro formato, que hubo de ser realizada hacia 1579. Estaba entre las pinturas inventariadas entre los bienes del riojano, a su fallecimiento.

${ }^{16}$ Tampoco aparecen en el Indice de las pinturas al olio originales y sus respectibos profesores, de este Real Casa y Monasterio de san Lorenzo de El Escorial (ms. anónimo, ca, 1800). Cfr. B. Bassegoda i Huigas, «El Escorial como museo o galería de pinturas», en VV.AA. , Felipe II y el arte de su tiempo, Madrid, 1998, pp. 159 y ss.

17 V. Poleró, Catálogo de los cuadros del Real monasterio de San Lorenzo llamado de El escorial, Madrid, 1857, núms 174 y ss.

18 Asegura además que por las ocho pinturas se pagaron a El Mudo 1900 ducados y no los 1600 en que fueron ajustadas.

19 A. Ceán Bermúdez, Diccionario histórico de los más ilutre profesores de las Bellas Arte en España, Madrid, 1800, vol. II, p. 96.

${ }^{20}$ J. Zarco Cuevas, Pintores españoles..., p. 17 n. 18; R. Mulcahy, Navarrete El Mudo, pintor de Felipe II, 1999, p. 38 .

AEA, LXXV, 2002, 298, pp. 191 a 216 
retiradas — nada dicen del San Juan-, pero admiten que acaso no fueran enteramente destruidas y que pudieran haber pasado a otro templo, figurando como anónimas o mal atribuidas ${ }^{21}$. Así se puede entender tambien por Palomino, en su Parnaso español pintoresco laureado (1724), si bien su referencia es demasiado genérica para que se tome como testimonio fiel ${ }^{22}$. La idea de que el San Juan en Patmos sólo sufrió quizá un deterioro parcial fue suscitada ya con anterioridad por Benito G. Mur, a la luz de la mención que de ella hace en 1698 el P. de los Santos ${ }^{23}$, pero esta apreciación se origina en que la primera edición de la Descripción breve del monasterio de San Lorenzo el Real es de 1657, catorce años antes del incendio, y el dato no se corrigió en la aparecida 27 años después del suceso, como bien se ha hecho notar ${ }^{24}$. La cuestión fue planteada bajo la inverosímil consideración de que la pintura hoy perteneciente al Museo de San Telmo, en San Sebastián, fuera el original supuestamente destruido, lo que Trinidad de Antonio rebate con sólidos argumentos (técnica prieta, dibujos preciso, ejecución a la manera flamenca, y distanciamiento del estilo seguido por el Mudo hacia 1575$)$, a los que hay que unir su formato apaisado $(1.60 \times 2.10 \mathrm{~m}$.) y la nula correspondencia de sus medidas con la Adoración de los Pastores de El Escorial $(2.50 \times 2.10 \mathrm{~m}$. y las otras pinturas de la primera y la segunda entrega. El asunto ha sido retomado sin embargo con algunas reservas por Francisco Fernández Pardo en catálogo de la exposición monográfica celebrada en 1995, sobre los mismos argumentos expuestos por Mur y con alguna otra endeble apoyatura bibliográfica ${ }^{25}$. De Antonio pone de relieve que el lienzo de San Juan pertenecía a la segundas cuatro de las ocho pinturas, que «...no acabó tanto y puso más cuidado en dar fuerza y relieve a lo que hacia, imitando la manera del Tiziano en los oscuros y las fuerzas» ${ }^{26}$, y sería según su criterio obra datable ya por 1575 y lejana del estilo apurado del Bautismo de Cristo que presentara el riojano hacia 1565 a Felipe II como prueba de su pericia artística. Sin ningún género de dudas la interesada atribución a Navarrete de la pintura del Museo de San Telmo es de todo punto recusable ${ }^{27}$, pues nada hay en ella que tenga que ver ni remotamente con su estilo.

En el Museo diocesano de Segovia existe sin embargo un lienzo de San Juan en Patmos ${ }^{28}$ que responde por entero a los aspectos iconográficos del original de Navarrete que detalla el

\footnotetext{
${ }^{21}$ En anejo a A.E.A. núm. 179, XLV, 1972. Sobre los efectos del incendio, el mismo G- de Andrés ha dado en otros casos la pintura por destruida (El Incendio de El monasterio de El Escorial del año 1671. Sus consecuencias en el arte y las letras, Madrid, 1979, p. 25). El testimonio más próximo es el del P. Juan de Toledo (vid. $\mathrm{G}$ de Andrés, «Relación historial del incendio y reconstrucción del monasterio de El Escorial [1671-1677], por el padre Juan de Toledo», Hispania Sacra, XXIX, 1976, pp. 77-89) quien nada detalla sobre ésta y muchas otras pinturas.

${ }^{22}$ En realidad sigue a Sigüenza, y tras hablar de los cuadros que Navarrete hizo para las dos sacristías declara «Estos ocho cuadros grandes, son los que ahora están en el claustro alto», vid. A.Palomonio, Museo pictórico y Escala óptica, ed. de Madrid, 1947, p. 788.

${ }^{23}$ B. G. Mur, «Sobre un cuadro de Navarrete el Mudo», B.S.E.E., XXVIII, 1920, pp. 216-225. Según él, interesado propietario entonces de la pintura, hay evidencias de que no se destruyó en los incendios de 1577 , $1671,1732,1764$ y 1826.

${ }^{24}$ T. de Antonio Sáenz, Pintura española del último tercio del siglo XVI en Madrid: Juan Fernández de Navarrete, Luis de Carvajal y Diego de Urbina. tesis inédita, Universidad Complutense, 1987, p. 157. Las sucesivas edificiones del libro del P. de los Santos fueron incorporando datos nuevos sobre la temática y paradero de diferentes pinturas.

25 Navarrete «el Mudo», pintor de Felipe II (seguidores y copias),catálogo.de la exposición , pp. 280-281.. Cita a Mayoral y Parracia «Estudio sobre el pintor Juan Fernández Navarrete el Mudo...». Logroño, 1900. p. 11; Zarco Cuevas.»Pintores españoles en San Lorenzo el Real de El Escorial. Juan Fernández Navarrete el Mudo Arte Español, X, n. 4. 1930, p. 111

26 Sigüenza, op. cit., p. 243. ; citado por Trinidad de Antonio , loc cit.

27 En ello incide Rosemarie Mulcahy ( «Obras atribuidas a Navarrete: una valoración», en Navarrete «El Mudo» y el ambiente artístico riojano, V Jornadas del Arte Riojano, Logroño, 1995,. p. 67) en su rigurosa revisión de las obras consideradas en algún momento de El Mudo y de algunos desatinos vertidos en el catálogo de la exposición celebrada poco antes.

${ }^{28}$ Fichero-inventario del museo, núm. 74P
}

$A E A, \mathrm{LXXV}, 2002,298$, pp. 191 a 216 

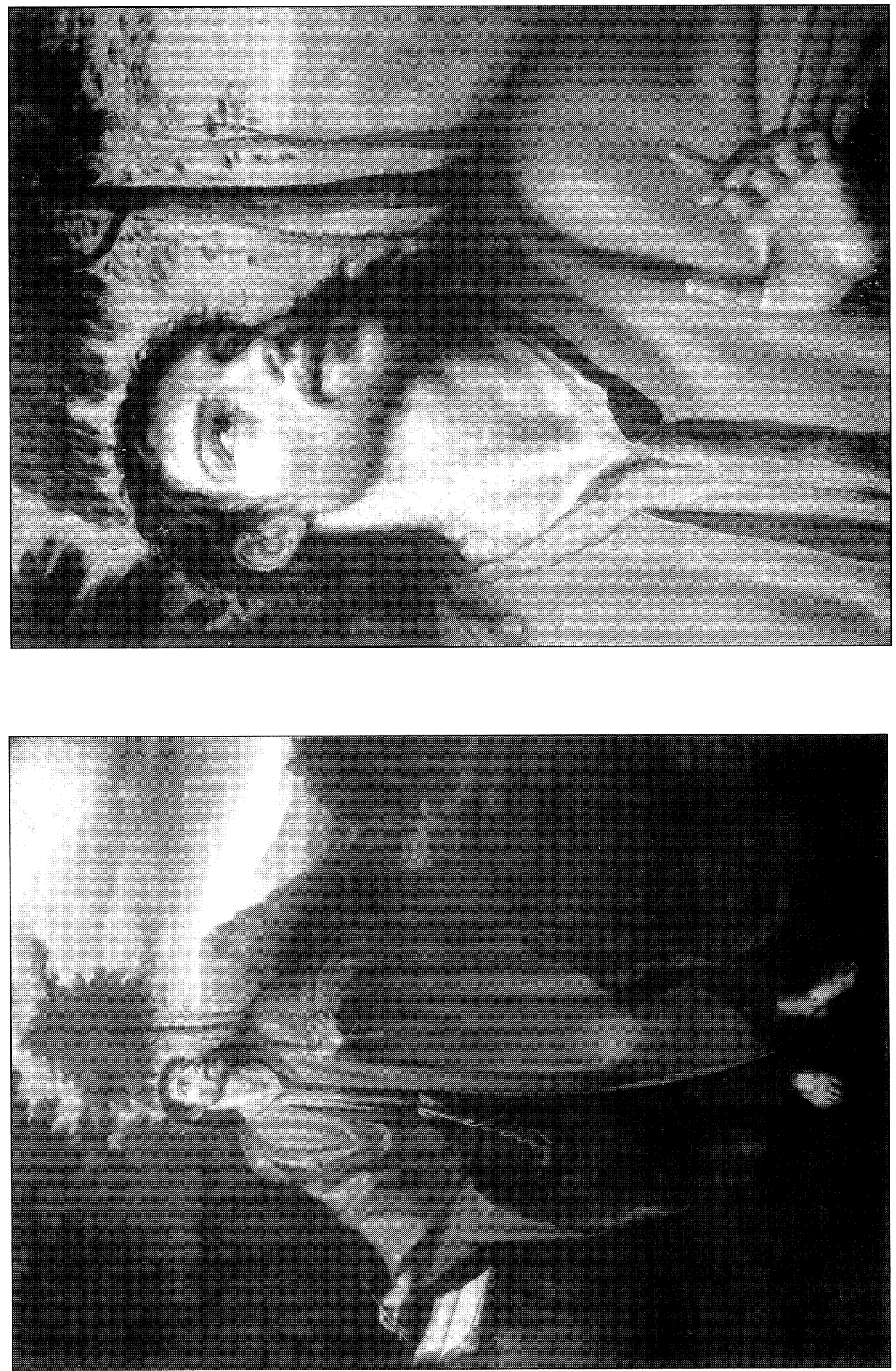
P. Sigüenza y posee rasgos que lo relacionan de manera estrecha con el arte de El Mudo, aunque no tanto con el estilo característico de su producción más avanzada. Sólo sus medidas $(142.5 \times 101.5 \mathrm{~cm}$.), sensiblemente inferiores a las de los lienzos de las dos serie pintadas para las sacristías provisionales de la basílica, obligan a descartar de manera absoluta que se trate del tan traído y llevado San Juan Evangelista, que hay que dar definitivamente por destruido $^{29}$. Pero todo indica que esta notabilísima pintura de procedencia desconocida, hoy en la sala del Trono del palacio episcopal de Segovia, tiene que ver con aquel original escurialense. El joven apóstol, con túnica talar azul y manto rojo-anaranjado, figura en pie junto a una roca, sobre la que descansa abierto el libro revelado, y mira hacia lo alto, donde apenas alcanza a advertirse la distante presencia luminosa de la mujer apocalíptica, al tiempo que con gesto de inspiración detiene en el aire la pluma con que escribe. Al lado aparece el águila, posada en tierra y mirando hacia un sapo apostado en el borde de una pequeña charca, y detrás se abre un profundo paisaje, envuelto en una atmósfera intensamente húmeda, con fríos lejos azules, en rotundas montañas rocosas, y esbeltos árboles cercanos de un inusitado verdor. Se diría, en efecto, que Sigüenza describe realmente ésta y no otra pintura Es cierto que el jerónimo habla del evangelista como «vestido de ropas, con mucho adorno», pero no ha de inferirse de ello que el atuendo fuera suntuoso - bien habría afeado el historiador la impropiedad del caso-, y ha de notarse que matiza la frase con un corrector "grave y hermoso», evidenciando lo equívoco de la expresión adorno, que no ha de suponer sino cuidado y, a lo sumo, complejidad en el drapeado. La pintura permite concretar, por otro lado, que lo de «algunas visiones sagradas, muy remontadas» se refiere a la aparición de la mujer apocalíptica en lo alto (Ap.12), complemento iconográfico usual del tema, y nunca a otras visiones, y el mismo autor advierte sobre lo casi imperceptible de este pormenor, cosa aquí patente. La descripción del águila desalada abatiéndose sobre una rana parece evocar desde luego la imagen de un ave descendiendo de lo alto hacia una charca, pero ni necesariamente había de ser así ni tendría fundamento iconográfico, y la idea hubo de ser por consiguiente exactamente lo plasmado en esta pintura ${ }^{30}$ : un águila quieta, al pie del santo, según es habitual, y dirigiendo su mirada hacia un viscoso sapo, símbolo de las miserias humanas ${ }^{31}$. Y el «singular meneo» de la figura del evangelista, de «elevado el rostro, con un escorzo acertadísimo», y la referencia a «la campaña y los lejos llenos de arboleda y frescura», son otros datos relevantes de una descripción ceñida palabra por palabra al lienzo que nos ocupa, a lo que debe añadirse el dato sobre el color del manto facilitado en el registro de las entregas a El Escorial.

Hay que descartar ante todo que el autor de tan notable creación fuera el siempre desigual Alonso de Herrera, joven amigo y modesto seguidor en Segovia de El Mudo, de estilo hoy perfectamente conocido. Uno de los rasgos de su pintura, demasiado apegada en general a modelos manieristas y ecléctica en sus referentes, es una excesiva blandura y una tendencia a las formas chatas que desprovee a sus modelos figurativos de vigor, cuando no de base estructural ósea, incluso aquellos concebidos desde una navarretesca y monumental interpretación a partir de los apóstoles de El Escorial ${ }^{32}$. No hay duda de que Herrera, en modo algu-

\footnotetext{
${ }^{29}$ No hay datos exactos del lienzo realizado para El Escorial, pero a tenor de los cinco conservados y de su analogía en tamaño con el Cristo a la columna, referida en la segunda entrega, hubo de ser pintura de unos $3.50 \mathrm{~m}$. de alto.

${ }^{30}$ Se trata de la parte del lienzo que más ha sufrido, y es de creer que este pormenor, de aspecto hoy algo monocromático- gozó en origen de una mayor nitidez. La figura del águila aparece bastante desvaída.El lienzo fue restaurado hace algunos años por la señora Herreros. Agradezco la información a Carlos Sánchez Díez, que prepara un estudio sobre los fondos del museo diocesano.

31 Sobre el águila a punto de abatirse sobre la rana, dice Sigüenza «así lo hizo el Verbo Eterno para sacarnos del lodo de nuestra miseria...» (loc. cit.)

${ }^{32}$ Véasé el San Bartolomé de Cobos de Segovia y el del Museo Provincial de esta ciudad. Mayor distancia si cabe hay en el tratamiento del paisaje.
}

AEA, LXXV, 2002, 298, pp. 191 a 216 
no falto de oficio y de recursos estilísticos - ejemplo singular lo tenemos en el esprangueriano San Juan en Patmos de Hontoria-, aunque afincado por lo común en un hacer rutinario, carecía de capacidad y de criterio para dar forma a una obra así. Hay que significar, sin embargo, que en el mismo monasterio filipino se guarda una pintura de los Santos Juanes, atribuida recientemente al segoviano ${ }^{33}$, en la que el Evangelista aparece en idéntica postura que en el lienzo del museo diocesano; y en el Museo Provincial de Segovia existe otra modesta pintura de los Santos Juanes, perteneciente a una serie de parejas de santos de inspiración escurialense asignada por el marqués de Lozoya a Nicolás Greco ${ }^{34}$, en la que el Bautista sigue el modelo del lienzo de Tiziano llegado en 1574 a El Escorial y el Evangelista repite la figura que venimos considerando ${ }^{35}$.

Hay, así, sobrados motivos para estimar que este espléndido San Juan en Patmos del Museo episcopal de Segovia es obra del propio Navarrete. Y, en tal sentido, no está de más recordar que a la muerte de El Mudo quedaron en su aposento dos cuadros, uno de San Juan Bautista y otro de San Juan Evangelista que fueron entregados por su hermano al veedor García de Brizuela para que pasaran a poder del monarca ${ }^{36}$. Estas pinturas, dibujadas y bosquejadas por El Mudo, serían terminadas por un oficial de Luqueto y finalmente entregadas al monasterio en $1584{ }^{37}$. Sin embargo, es claro que no estamos ante una obra que pueda relacionarse con el estilo maduro del riojano, y nada hay aquí que recuerde a la manera de Luca Cambiaso; antes al contrario, todo apunta hacia un momento transitorio en la primera fase de la producción escurialense de Navarrete, después del Bautismo de Cristo del Museo del Prado (ca, 1565) y no lejos de sus creaciones firmadas en 1569 o 1571, como el San Jerónimo penitente y el Martirio de Santiago.

Un análisis pormenorizado lleva a reconocer aquí la calidad pictórica y los recursos técnicos del artista. La misma solidez de la figura, preludio de los apóstoles de los altares menores de la basílica, y la concepción del paisaje, conectable con el de San Jerónimo penitente, pero de mayor sencillez y algo más sumaria ejecución, son propios del hacer de Navarrete, aunque carentes de la fluidez pictórica de que empezó a hacer gala ya por $1571{ }^{38}$. El valiente escorzo con que se resuelve la soberbia cabeza del apóstol y cierta blandura casi mórbida del rostro, concertada con la delicadeza en las facciones, hablan aún de recursos tipológicos manieristas y no tanto del rotundo naturalismo plástico de sus parejas de santos, pero la misma fortaleza de los pies y del cuello, la amplitud del manto - reelaborado en las ropas del San Lucas evangelista del altar basilical_, o la mano levantada, que repite en el Martirio de Santiago, se suman a la monumental concepción figurativa, a la riqueza de los matices pictóricos y al particular sentido del paisaje, en apoyo de la atribución propuesta. Todo ello mue-

\footnotetext{
${ }^{33}$ Catálogo de la exposición de 1995,. n . 27; J. Zarco Cueva, (Pintores españoles..., p. 18) se lo asignó a Navarrete; también se consideró en algún momento obra temprana de El Greco, coca enteramente esestimada. La atribución de García-Frías no carece de fundamento, especialemente en atención a la figura del Bautista.

${ }^{34}$ M. de Lozoya , «Nicolás, el 'Greco segoviano'», A.E.A. , XLIII, 1970..), p. 8; F. Collar de Cáceres, Pintura en la antigua diócesis de Segovia, 1500-1631, Segovia 1989, vol. 1, p.310.

${ }^{35}$ García-Frías estima que en la versión asignada Herrera el Bautista se adapta también el modelo de Tiziano, cosa bastante discutible.

${ }^{36}$ Ceán Bermúndez, op. cit, , vol. II, p.107; Trinidad de Antonio, op. cit. p. 158, núm 26. García Frías (en Catálogo de la exposición de 1995..p. 317), cree que es la evidencia de una fuente común con el pequeño lienzo de El Escorial que seguramente era una obra del riojano.

${ }^{37}$ Libro de Cuarta Entrega, pp.92 y 96. Citado por C. García Frías, loc. cit, núm. 27. Cf. Julián Zarco Cuevas, «Inventario de las alhasjas...», B.R.A.H., núm. 97, 1930, pp. 35-36, núms. 916 y 924

${ }^{38}$ Una primera muestra de ello en el paisaje del Martirio de Santiago, firmado este año. El trabajo de copista y restaurador desempeñado en los inicios de escurialenses, en contacto no sólo con el arte de Tiziano sino también con obras flamencas del siglo $\mathrm{xv}$, hablan de su ductilidad y su capacidad para una pintura de dibujo seguro y de técnica apurada. En el extremo contrario está el tizianesco ángel del evangelista San Mateo, de las parejas de apóstoles en los altares menores.
} 
ve a considerar que, a pesar de la estimación global de Sigüenza, es probable que el destruido San Juan en Patmos de El Escorial no fuera obra que supusiera «tanta mudanza» con relación a las cuatro pinturas de la sacristía de prestado y que en realidad su creación tuviera lugar por 1572 y antecediera a la de la Adoración de los Pastores y la Sagrada Familia con San Joaquín y Santa Ana, aproximándose en lo estilístico al San Jerónimo y al Martirio de Santiago, como ocurre en este lienzo del museo diocesano, que bien pudo preceder a la versión definitiva ${ }^{39}$ y en el que ni se aprecia la intervención de dos manos ni hay nada de la última manera de Navarrete, lo cual excluye que sea una de las pinturas inconclusas entregadas a García de Brizuela. Así, la sensación de una fragilidad y estilización figurativa y de un sentido de las texturas ajenos al hacer de El Mudo encuentra un adecuado engarce en su evolución estilística, fuera ya de la excesiva definición dibujada de las formas aún patente por 1571 y antes de los desleimientos pictóricos de su obra madura ${ }^{40}$, y se verifica con una complacencia en mostrar la suavidad de la incipiente barba del joven apóstol y la riqueza de los matices cutáneos faciales denotadoras de un elevado grado de maestría técnica; y si bien el escorzo de la hermosa cabeza del santo difiere del más sólido y «correcto» de Santiago en la pintura de su martirio - como éste del de algún otro-, no puede dejar de notarse, abundando en lo ya estimado, una singular proximidad en aspectos como el tratamiento del cabello o el modo en que están pintadas las ojeras y algún pequeño pliegue facial, y la misma forma nasal, delgada y algo puntiaguda, es versión escorzada de la habitual en sus modelo figurativos más delicados. Habra así que concluir que se trata de una primera o quizá segunda versión del San Juan en Patmos de El Escorial, de la que no queda memoria, y que corresponde a un momento de transición estilística en la producción temprana de Navarrete en los inicios de su trayectoria escurialense.

Fernando Collar de CÁceres Universidad Autónoma de Madrid

\section{FLORES, FERNÁNDEZ Y OLIVA: TRES AZULEJEROS PARA LAS OBRAS REALES DE FELIPE II}

Que las obras de arquitectura promocionadas por Felipe II eran acabadas frecuentemente con revestimientos de azulejos es una idea conocida desde hace tiempo. El ejemplo más frecuentemente aducido es el de los aposentos del mismo rey en el Monasterio de San Lorenzo de El Escorial aunque podrían ser citados muchos más casos conservados y otros conocidos a través de la documentación. Este rasgo de la arquitectura filipina y el personal interés del rey por el asunto debió ser un importante acicate para el desarrollo de la azulejería española en la segunda mitad del siglo xVI '.

\footnotetext{
${ }^{39}$ En tal sentido se refiere a la Flagelación de Cristo después de hablar de la Adoración de lo Pastores y de la Sagrada Familia con San Joaquín y Santa Ana, aparte de lo relativo a la pintura de San Juan. El criterio es del todo claro cuando habla de las pinturas de la sacristía de Prestado, que comienza con la «muy acabada» pintura de la Asunción de la Virgen, para seguir con la del martirio de San Felipe, «algo desgraciado por el colorido de las ropas», y pasar luego a San Jerónimo penitente y al Martirio de Santiago.

${ }^{40}$ Ambos extremos concurren en el Martirio de Santiago, de 1571, manteniendo en buena manera las figuras principales la solidez dibujada de su San Jerónimo penitente e inaugurando el paisaje, con sus figuras casi inmateriales, la factura cromática y abocetada de su producción posterior, bien patente en lo lejos de las parejas de apóstoles y en algunas figuras de singular concepto veneciano, como el ángel de San Mateo.

' Sobre este período talaverano pueden consultarse: Vaca y González, Diodoro y Ruiz de Luna, Juan: La cerámica de Talavera de la Reina y algunos datos sobre la de Puente del Arzobispo. Madrid, 1943; Alice Wilson
} 